\title{
EDITORIAL
}

\section{LIFE STYLE AND HEALTH EDUCATION}

\author{
Iftikhar Ahmad \\ Department of Community Medicine, Gomal Medical College, D.I.Khan, Pakistan
}

Lifestyle is the interest, behavior, opinion, style of living or world outlook of an individual, group, or culture; a combination of tangible factors like demographics and intangible factors like personal values and preferences. ${ }^{1}$

Recently researchers have more interest in the relationship between life style and health. Millions of people, following unhealthy lifestyle (or risk-factors), are plagued with morbidity, disability and mortality due to non-communicable, communicable diseases \& nutritional disorders. Persons having unhealthy behaviors may be called as 'at risk groups'. ${ }^{2}$ Although a healthy lifestyle has consistently been shown to decrease mortality, the population prevalence of healthy living remains low. ${ }^{3}$

The mental health of an individual can be assessed by his behavior and attitude. Common lifestyle variables influencing health include diet, exercise, sleep, smoking, alcohol consumption, substance abuse, stress management, sexual behavior, internet, recreation, etc. ${ }^{4}$ Besides, weight management, exposure to the sun, social contact, work life balance, leisure activities, screening for cancer etc. make a healthy life style. Healthy ways of living are developed through processes of socialization with parents, friends, relatives and community. However, not all life style factors are harmful. There are many life styles that promote health. For example, adequate nutrition, exercise, meditation, enough sleep etc. ${ }^{5}$

Modern or slow epidemics of non-communicable diseases (NCDs) e.g. hypertension (HTN), coronary heart disease (CHD), diabetes mellitus (DM), obesity, cancer etc. have been increasing in incidence compared to the previous century. With the increase in life expectancy, the prevalence of NCDs is on the rise. About 2 billion people are overweight in developed as well as low to middle income countries. ${ }^{6}$ Comorbidities of obesity include HTN, CHD, DM, stroke, cancers, gallbladder disease, dyslipidaemia, osteoarthritis, gout and sleep apnoea. ${ }^{7}$ Obesity is not only preventable but treatable with lifestyle modifications to forestall DM. ${ }^{8}$ Furthermore, several pathways linking obesity and CHD have been described; in particular coronary atherosclerosis, heart failure, and atrial fibrillation. ${ }^{9}$ In a study by CDC conducted in late 1970 s in US, approximately $48 \%$ of all premature deaths prior to age 75 years could be traced to one's lifestyle or health behavior choices, hence focusing on a personal responsibility model whereas another study accounts for about $63 \%$ of all deaths. ${ }^{10}$

Human behavior is a major obstacle to disease control. Changes in human behavior may prevent most of the world's major health problems \& premature deaths at low cost. Public health is defined as 'the health status of a defined group of people and the governmental actions and conditions at the local, state, and national levels to promote healthy behaviors, prevent spread of disease and injuries, protect against environmental hazards \& disasters and assure the curative and rehabilitative health services. Many public health recommendations and clinical guidelines emphasize that healthy lifestyles have substantial health benefits. ${ }^{11}$

KEY WORDS: Coronary atherosclerosis; Atrial fibrillation; Premature deaths; Cardiorespiratory fitness; Risk factors; Antihypertensive medications.

This article may be cited as: Ahmad I. Life style and health education [editorial]. Gomal J Med Sci 2019 JulSep: 17 (3): 63-4. https://doi.org/10.46903/gjms/17.03.2079

\section{Corresponding Author:}

Professor Iftikhar Ahmad

Department of Community Medicine

Gomal Medical College, D.I.Khan, Pakistan.

E-mail: iftikharahmadgandapur@yahoo.com

Date Submitted: 12-05-2019

Date Revised: $\quad$ 02-06-2019

Date Accepted: 27-06-2019
Changes in the life-style of the population by health education encompass three approaches of primary prevention as recommended by the WHO for prevention of chronic diseases. In first approach or primordial prevention, children are discouraged from adopting harmful lifestyles through individual/ mass education in countries in which many adult health problems (e.g., obesity, hypertension) have not yet appeared. Lifestyles are formed during childhood 
and aim is to prevent the emergence of risk factors. Second approach or population (mass) strategy is directed at the whole population, irrespective of individual risk level. A small reduction in the average blood pressure/ serum cholesterol in the community, helps in reducing the CHD prevalence. Third approach or high-risk strategy, on the other hand, aims to detect individuals at high risk by the optimum use of clinical methods and provide preventive care to them. To have an impact on the population, all the above three approaches should be implemented as they are usually complementary but the results are perceived after several decades and not immediately. Besides health education the population must have access to preventive measures. ${ }^{5}$

Lifestyle medicine program serves as a systematized approach to manage NCDS by addressing multiple risk factors through self-management skills. ${ }^{12}$ Physical activity leading to cardiorespiratory fitness is needed in all age groups, both sexes, race \& ethnicities to prevent NCDs including CVDs. ${ }^{13}$ Better control of behavioral risk factors alone could prevent onethird of all acute and two-thirds of chronic disabilities. Physical activity, consumption of fresh rather than processed foods, limited use of cooking/ table salt to $<5 \mathrm{~g}$ / day per caput, avoiding coconut oil, vanaspati and fats of animal origin except fish, encouraging fruits \& vegetables and caloric intake according to body needs are important. Lifestyle modifications should continue despite antihypertensive medications, since there is evidence that the number and dose of medications required is minimized. ${ }^{14}$

\section{REFERENCES}

1. Lifestyle (sociology). Wikipedia. [accessed 2019 Apr 2]. Available at: https://en.wikipedia.org/wiki/ Lifestyle_(sociology)

2. Gupta MC, Mahajan BK. Textbook of Preventive and Social Medicine, 3rd ed. New Delhi: Jaypee Brothers; 2003. p. 66-80.https://doi.org/10.5005/ jp/books/10951_8

3. Manton KG. The global impact of noncommunicable diseases: estimates and projections. World
Health Stat Q 1988;41(3-4):255-66.

4. Farhud DD. Impact of lifestyle on health. Iran J Public Health 2015 Nov; 44(11): 1442-4.

5. Park K. Park's Textbook of Preventive and Social Medicine, 18th ed. Jabalpur: Banarsidas Bhanot; 2005. p.606-21.

6. Seidell JC, Halberstadt J. The global burden of obesity and the challenges of prevention. Ann Nutr Metab 2015; 66 Suppl 2:7-12. https://doi. org/10.1159/000375143

7. Jakicic JM, Davis KK. Obesity and physical activity. Psychiatr Clin North Am 2011;34(4): 829-40. https://doi.org/10.1016/j.psc.2011.08.009

8. Carbone S, Del Buono MG, Ozemek C, Lavie CJ. Obesity, risk of diabetes and role of physical activity, exercise training and cardiorespiratory fitness. Prog Cardiovasc Dis 2019;62(4): 327-33. https://doi.org/10.1016/j.pcad.2019.08.004

9. Mandviwala T, Khalid U, Deswal A. Obesity and cardiovascular disease: a risk factor or a risk marker? Curr Atheroscler Rep 2016;18(5): 21. https://doi.org/10.1007/s11883-016-0575-4

10. Prabhakara GN. Short Textbook of Preventive and Social Medicine. 1st ed. New Delhi: Jaypee Brothers; 2002. p.81-6.

11. Reeves MJ, Rafferty AP. Healthy lifestyle characteristics among adults in the United States, 2000. Arch Intern Med 2005;165(8): 854-7. https://doi. org/10.1001/archinte.165.8.854

12. Kushner RF, Sorensen KW. Lifestyle medicine: the future of chronic disease management. Curr Opin Endocrinol Diabetes Obes 2013;20(5): 389-95. https://doi.org/10.1097/01. med.0000433056.76699.5d

13. Lavie CJ, Ozemek C, Carbone S, Katzmarzyk PT, Blair SN. Sedentary behavior, exercise, and cardiovascular health. Circ Res 2019 Mar 1;124(5): 799-815. https://doi.org/10.1161/CIRCRESAHA.118.312669

14. Zellner C, Sudhir K. Lifestyle modifications for hypertension. The many benefits are worth the effort. Postgrad Med 1996 Oct;100(4): 75-80. https://doi.org/10.3810/pgm.1996.10.91

\section{CONFLICT OF INTEREST \\ Authors declare no conflict of interest. GRANT SUPPORT AND FINANCIAL DISCLOSURE None declared.}

